\title{
Dental Education in Kuwait
}

\author{
J.M. Behbehani \\ Faculty of Dentistry, Health Sciences Center, Kuwait University, Kuwait
}

\section{Key Words}

Dental education · Curriculum • Evidence-based approach · Community-based learning · Comprehensive dental care

\begin{abstract}
For a long time there has been a need to establish a dental school in Kuwait, due to the fact that the majority of dentists working in Kuwait are expatriates from various countries. An Amiri decree in 1996 made it possible, and the first dental students were admitted to the Kuwait University Faculty of Dentistry in 1998. The mission of the Faculty of Dentistry is 'to promote oral health in Kuwait through education, research and cooperation with other professional health care institutions as well as the community at large'. A 6.5-year dental curriculum was completed after 2 years of committee work and was accepted by the University Council in 2001 . This curriculum incorporates current trends in medical and dental education, such as the evidence-based and community-based approaches, problem-solving methodology for outcomebased learning, and competency achieved through comprehensive patient care.
\end{abstract}

Copyright $@ 2003$ S. Karger AG, Basel

\section{Introduction}

Dental care in Kuwait is delivered by expatriates as well as Kuwaiti dentists who received their training abroad, mainly in Egypt, the United States, the United Kingdom, and the Republic of Ireland. While the Faculty of Medicine was established at Kuwait University in 1973, plans for establishing a Faculty of Dentistry did not start until the early 1980s. The Gulf War delayed these plans until May 26th, 1996, when an Amiri decree was issued for the establishment of the Faculty of Dentistry. The first class of 26 students was admitted to the dental program in September 1998, and they will graduate in January 2005.

Once the Faculty of Dentistry was established, a curriculum committee was set up to plan, evaluate and revise the program. The dental curriculum is presently a $6.5-$ year, 13-semester program, including 1.5 years or 3 semesters of preprofessional studies in the Faculty of Science, 2.5 years or 5 semesters of preclinical courses in the Faculty of Medicine, and finally 2.5 years or 5 semesters of clinical training in the Faculty of Dentistry. Dental subjects were incorporated into both the preprofessional and preclinical programs in order to expose the students to clinical experiences early in their training, and medical courses which were less relevant to dentistry were replaced by dental courses (fig. 1). For instance, the Introduction to the Dental Profession course was incorporated into the preprofessional program in the 2 nd year, and

Dr. Jawad M. Behbehani

Faculty of Dentistry, Health Sciences Center, Kuwait University PO Box 24923

Safat 13110 (Kuwait)

Tel. +965 2664502, ext. 7101, Fax +965 2634247, E-Mail jawadbeh@hsc.kuniv.edu.kw
Fax + 41613061234 E-Mail karger@karger.ch www.karger.com

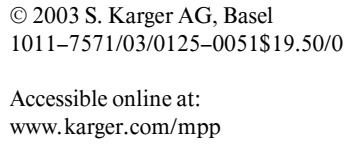


Table 1 (continued)

b Preclinical program

\begin{tabular}{llr}
\hline $\begin{array}{l}\text { Depart- } \\
\text { ment }\end{array}$ & $\begin{array}{l}\text { Course } \\
\text { No. }\end{array}$ & Course \\
\hline Year 2, semester 2 & \\
302 & Anatomy & 6 \\
302 & Behavioral Science & 2 \\
302 & Biochemistry & 4 \\
302 & Physiology & 4 \\
\hline & & 16 \\
\hline Year 3, semester 1 & \\
303 & Anatomy & 6 \\
303 & Behavioral Science & 2 \\
303 & Biochemistry & 4 \\
303 & Physiology & 4 \\
& & 16
\end{tabular}

\begin{tabular}{|c|c|c|c|}
\hline \multirow{2}{*}{\multicolumn{4}{|c|}{ Year 3 , semester 2}} \\
\hline & & & \\
\hline & 304D & Anatomy & 6 \\
\hline & 304 & Behavioral Science & 2 \\
\hline & 304 & Biochemistry & 4 \\
\hline & 304 & Physiology & 4 \\
\hline & & & 16 \\
\hline \multicolumn{4}{|c|}{ Year 4, semester 1} \\
\hline & 400 & Pathology & 4 \\
\hline & 400D & Microbiology/Oral Microbiology & 4 \\
\hline & 400 & Pharmacology & 3 \\
\hline & 400D & Neuroscience/Oral Neuroscience & 3 \\
\hline & & & \\
\hline \multicolumn{4}{|c|}{ Year 4, semester 2} \\
\hline & 401D & Oral and Systemic Pathology & 4 \\
\hline & 401 & Pharmacology & 3 \\
\hline & 401D & Neuroscience/Oral Neuroscience & 3 \\
\hline 10 & 411 & Dental Biomaterials & 2 \\
\hline 30 & 431 & Preclinical Oral and Maxillofacial Radiology & 2 \\
\hline 40 & 441 & Dental Anatomy and Function & 2 \\
\hline 40 & 442 & Preclinical Operative Dentistry and Cariology & 4 \\
\hline 40 & 443 & Preclinical Removable Prosthodontics & 2 \\
\hline
\end{tabular}

The grand total credit hours for the Bachelor of Medical Sciences (BMedSc) degree in the dental program is 132 , comprising $48 \mathrm{CH}$ in the preprofessional program and $84 \mathrm{CH}$ in the preclinical program.

The grand total credit hours for the Bachelor of Dental Medicine (BDM) degree is $236 \mathrm{CH}$ comprising $48 \mathrm{CH}$ in the preprofessional program, $84 \mathrm{CH}$ in the preclinical program and $104 \mathrm{CH}$ in the dental clinical educational program. Departments in the Faculty of Dentistry (Faculty No. 12) as referred to in this Major Sheet: Department of Bioclinical Sciences $(B C S)=$ No. 10, Department of Developmental and Preventive Sciences $($ DPS $)=$ No. 20, Department of Diagnostic Sciences $(\mathrm{DS})=$ No. 30, Department of Restorative Sciences $(\mathrm{RS})=$ No. 40, Department of Surgical Sciences $($ SS $)=$ No. 50, Nondepartmental activities coordinated by the Vice-Deans $=$ No. 00 .

1 Coordinated by the Vice-Dean for Academic Affairs.

2 Coordinated by the Vice-Dean for Research.

3 Coordinated by the Vice-Dean for Research.
Table 1 (continued)

c Dental clinical educational program

\begin{tabular}{lll}
\hline $\begin{array}{l}\text { Depart- } \\
\text { ment }\end{array}$ & Nourse Course & $\mathrm{CH}$ \\
& No.
\end{tabular}

Year 5, semester 1

$20 \quad 521 \quad$ Pediatric Dentistry I

$20 \quad 522 \quad$ Orthodontics I

$30 \quad 531 \quad$ Oral and Maxillofacial Radiology I

$30 \quad 532 \quad$ Principles in Medicine I 4

$40 \quad 541 \quad$ Prosthodontics I (Fixed)

$40 \quad 542 \quad$ Prosthodontics II (Removable) 2

$40 \quad 543 \quad$ Endodontics I 2

$50 \quad 551 \quad$ Periodontology I 2

$50 \quad 552 \quad$ Oral and Maxillofacial Surgery I 2

$00 \quad 501 \quad$ Comprehensive Dental Care $\mathrm{I}^{1} \quad 3$

23

Year 5, semester 2

$20 \quad 523 \quad$ Dental Public Health I (Preventive Dentistry) 2

$20 \quad 524 \quad$ Pediatric Dentistry II

$20 \quad 525 \quad$ Orthodontics II

$30 \quad 533 \quad$ Principles in Medicine II 4

$40 \quad 544 \quad$ Prosthodontics III (Fixed) 2

$40 \quad 545$ Operative Dentistry 3

$40 \quad 546 \quad$ Endodontics II 2

$50 \quad 553 \quad$ Periodontology II 2

$00 \quad 502 \quad$ Comprehensive Dental Care II $^{1}$

2

Year 6, semester 1

$20 \quad 621 \quad$ Pediatric Dentistry III 2

$20 \quad 622 \quad$ Dental Public Health II (Preventive Dentistry) 2

$20 \quad 623$ Dental Public Health III (Oral Epidemiology) 2

$20 \quad 624 \quad$ Orthodontics III 2

$30 \quad 631 \quad$ Principles in Medicine III 2

$30 \quad 632$ Oral Medicine and Clinical Oral Pathology I 2

$40 \quad 641 \quad$ Prosthodontics IV 2

$50 \quad 651 \quad$ Periodontology III 2

$50 \quad 652 \quad$ Oral and Maxillofacial Surgery II 2

$00 \quad 601 \quad$ Comprehensive Dental Care III ${ }^{1} \quad 4$

$00 \quad 602$ Community Rotation $\mathrm{I}^{2} \quad 2$

24

Year 6, semester 2

$\begin{array}{llll}20 & 625 & \text { Dental Public Health IV } & 2 \\ 20 & 626 & \text { Pediatric Dentistry IV } & 2 \\ 30 & 633 & \text { Oral and Maxillofacial Radiology II } & 2 \\ 30 & 635 & \text { Oral Medicine and Clinical Oral Pathology II } & 2 \\ 40 & 642 & \text { Prosthodontics V } & 3 \\ 50 & 653 & \text { Oral and Maxillofacial Surgery III } & 2 \\ 00 & 603 & \text { Comprehensive Dental Care IV }^{1} & 7 \\ 00 & 604 & \text { Community Rotation II } & 2 \\ & & & 22\end{array}$

Year 7 , semester 1

$\begin{array}{llll}00 & 701 & \text { Comprehensive Dental Care V } & 8 \\ 00 & 702 & \text { Community Rotation III }{ }^{2} & 3\end{array}$

$00 \quad 703$ Elective Project Study ${ }^{3} \quad 2$

\begin{tabular}{lr} 
& 13 \\
\hline Total $\mathrm{CH}$ & 104
\end{tabular}

Dental Education in Kuwait

Med Princ Pract 2003;12(suppl 1):51-55 
Table 2. The departmental structure of the Kuwait University Faculty of Dentistry

1 The Department of Bioclinical Sciences

Oral Biology

Oral Neurosciences

Oral Microbiology

Biomaterial Science

2 The Department of Developmental and Preventive Sciences Dental Public Health

Orthodontics

Pediatric Dentistry

3 The Department of Diagnostic Sciences Oral Pathology/Medicine

Oral and Maxillofacial Radiology

General Medicine

Temporomandibular Disorders

4 The Department of Restorative Sciences

Dental Anatomy and Function

Fixed/Removable Prosthodontics

Operative Dentistry

Endodontics

Dental Materials

5 The Department of Surgical Sciences

Periodontics

Oral and Maxillofacial Surgery

Table 3. Basic principles of dental education

1 Didactic and clinical education integrated with medicine

2 Competency-based curriculum

3 Comprehensive patient care clinical education

4 Emphasis on preventive dentistry and oral health promotion

5 Evidence-based approach, outcome-based education

6 Problem-solving methodology for treatment planning or case management

7 Promotion of ethical behavior and professionalism

8 Community-based learning

9 Lifelong learning

many pedagogical decisions for the core courses in the four faculties (Medicine, Dentistry, Pharmacy, and Allied Health Sciences and Nursing) of the Kuwait University Health Sciences Center (HSC). Dental students take the same preprofessional courses as other HSC students, plus the Introduction to the Dental Profession course in the 2nd year and an elaborate course in Principles in Medicine that is spread over the clinical years.
The community-based approach is introduced during the Introduction to the Dental Profession course and is emphasized in the Dental Public Health courses (II and III) during the first semester of the 6th year. Also in the 6th year, community rotations are arranged in cooperation with the Ministry of Health. As a future employer of our graduating dentists, the Ministry of Health plays an important role in the execution of the dental curriculum; several senior staff members of the Ministry of Health give lectures and supervise dental students in their community rotations and other extramural courses, while faculty members work 2 days a week in the Ministry of Health clinics. The community-based approach is also an integral part of some elective studies that require data collection from society and therefore rely on cooperation with community institutions.

Comprehensive dental care education involves adult dental care. Contrary to the department-/discipline-based model where a patient consults various specialists, each of whom treat the specific problems that fall into his or her field of expertise, one 'mentor' supervises all the treatment procedures across discipline borders. Students learn to treat the whole patient rather than see the patient as separate disease states. Courses on comprehensive dental care start in the first semester of the 5th year and continue until the end of the program. In addition, treatment planning seminars that comprehensively integrate various aspects of different disciplines are conducted in the clinics during the clinical years.

A competency-based curriculum lists the competencies to be achieved by the students by the end of the courses and uses an assessment system based on competency rather than clinical requirements for different treatment procedures. The courses in the clinical program are competency-based, and students must acquire competency in one area before moving on to the next.

Preventive dentistry and oral health promotion are emphasized in many classes throughout the dental program, and treated in detail in two separate courses on Dental Public Health (I and II) during the 5th and 6th years.

The evidence-based approach is used in several seminars that are part of traditional lecture courses as well as in comprehensive dental care clinical work. Students, patients, and colleagues can question the evidence presented, contrary to the traditional approach whereby no one questioned the experts. For an elective study project, students concentrate on the evidence-based approach and compile a comprehensive literature review. Students choose their topics, and advisors are nominated from the specific departments that specialize in those topics. 
The problem-solving methodology for treatment planning is introduced during the students' early exposure to patient clinics before the didactic clinical courses, as well as in the seminars about comprehensive dental treatment planning. Some studies have shown that problem-based learning is superior to traditional education $[5,6]$, but attempts to implement it in the dental program involved changing the teaching philosophy of the Faculty of Medicine. Therefore, the problem-based method is still not used very much, and lectures cover the bulk of didactic teaching.

The importance of ethics and professionalism is promoted in the course on Dental Public Health (IV) and by mentors who act as role models in comprehensive dental care clinics.

Finally, lifelong learning goals are adopted along with required computer literacy skills. Gathering information from the Internet is a major feature of all the courses, while elective studies concentrate on obtaining information from original publications rather than textbooks and reviews. The first Medline-based seminar is a part of the Introduction to the Dental Profession course.

The dental curriculum at Kuwait University is unique in that the students are exposed at an early stage to the healthcare system in Kuwait, when they go on their first field visits during the Introduction to the Dental Profession course in the 2 nd year. In fact, many practical training sessions take place in the national healthcare system, especially in the Kuwait School Health Programs where students implement preventive programs such as sealant and fluoride applications. Dentists from the Ministry of Health supervise students at the Ministry of Health dental clinics in the three community rotation courses during the last 2 years of the program, and they also give lectures at the university. In addition, subjects such as Oral Health in Kuwait, Healthcare Policy in Kuwait, School Oral Health Programs in Kuwait, and Legal Issues of Dentistry in Kuwait are covered in the Dental Public Health course (IV). Such integration with the national healthcare system has been strongly recommended by the WHO, but few colleges in the world have been able to accomplish it.

\section{Conclusions}

By incorporating the latest trends in the dental and healthcare professions, the new 6.5-year dental curriculum at Kuwait University's recently established Faculty of Dentistry aims to promote oral health in Kuwait through education and research as well as cooperation with healthcare institutions and the community. The program's emphasis on community involvement early in the program and the Faculty's close cooperation with the Ministry of Health make it unique to Kuwait. The curriculum was accepted in 2001 by the University Council, and it will be continuously scrutinized and revised as students proceed through the program in the coming years.

\section{Acknowledgments}

I am grateful to all of my colleagues in the Faculty of Dentistry, who contributed so much to creating the dental curriculum for the Faculty of Dentistry, Kuwait University.

\section{References}

1 Hausen H: Oral Health Sciences Education: Relevance to the Community. Geneva, World Consultation on Oral Sciences Education, WHO Workshop, 1994.

2 Formicola AJ, McIntosh J, Marshall S, Albert D, Mitchell-Lewis D, Zabos GP, Garfield R: Population-based primary care and dental education: A new role for dental schools. J Dent Educ 1999;63:331-338.
3 Harden RM: Curriculum change and the assessment of clinical competence. Proc First GCC Conf Faculties of Medicine, Medical Education in the GCC Countries. Kuwait, Faculty of Medicine, Kuwait University, Health Sciences Centre, 1999, pp 169-178.

4 Slavkin HC: The future of clinical dentistry. J Dent Educ 1998;62:751-755.
5 Norman GR, Schmidt HG: The psychological basis of problem-based learning: A review of the evidence. Acad Med 1992;67:557-565.

6 Albanese MA, Mitchell S: Problem-based learning: A review of literature on its outcomes and implementation issues. Acad Med 1993; 68:52-81. 